\title{
Erratum zu: Schein, E.H., \& Schein, P.A. (2018). Humble Leadership: The Power of Relationships, Openness, and Trust. Williston, VT, USA: Berrett-Koehler Publishers
}

\author{
Johannes Brunzel ${ }^{1}$
}

(c) Der/die Autoren 2021

\section{Erratum zu:}

\section{Gr Interakt Org 2020}

https://doi.org/10.1007/s11612-020-00513-1

Der Artikel Schein, E.H., \& Schein, P.A. (2018). Humble Leadership: The Power of Relationships, Openness, and Trust. Williston, VT, USA: Berrett-Koehler Publishers von Johannes Brunzel wurde ursprünglich ohne „Open Access“ Online First auf der Internetplattform des Verlags publiziert. Nach der Veröffentlichung im Band 51 Heft 2. 253 pp 254 entschied sich der Autor nachträglich für eine „Open Access"-Veröffentlichung. Das Urheberrecht des Artikels wurde deshalb zu (C Der/die Autor(en) 2021 geändert.

Funding Open Access funding enabled and organized by Projekt DEAL.

Open Access Dieser Artikel wird unter der Creative Commons Namensnennung 4.0 International Lizenz veröffentlicht, welche die Nutzung, Vervielfältigung, Bearbeitung, Verbreitung und Wiedergabe in jeglichem Medium und Format erlaubt, sofern Sie den/die ursprünglichen Autor(en) und die Quelle ordnungsgemäß nennen, einen Link zur Creative Commons Lizenz beifügen und angeben, ob Änderungen vorgenommen wurden.

Die in diesem Artikel enthaltenen Bilder und sonstiges Drittmaterial unterliegen ebenfalls der genannten Creative Commons Lizenz, sofern sich aus der Abbildungslegende nichts anderes ergibt. Sofern das betreffende Material nicht unter der genannten Creative Commons Lizenz steht und die betreffende Handlung nicht nach gesetzlichen Vorschriften erlaubt ist, ist für die oben aufgeführten Weiterverwendungen des Materials die Einwilligung des jeweiligen Rechteinhabers einzuholen.

Die Online-Version des Originalartikels ist unter https://doi.org/ 10.1007/s11612-020-00513-1 zu finden.

$\triangle$ Johannes Brunzel

brunzel.johannes@gmail.com

1 Institut für Unternehmensführung, Lehrstuhl für Organisation und Führung, Technische Universität Braunschweig, Abt-Jerusalem-Str. 4, 38106 Braunschweig, Deutschland
Weitere Details zur Lizenz entnehmen Sie bitte der Lizenzinformation auf http://creativecommons.org/licenses/by/4.0/deed.de. 